\title{
The geoelectric field: a link between the troposphere and solar variability
}

\author{
G. B. Burns, ${ }^{1}$ A.V. Frank-Kamenetsky, ${ }^{2}$ O. A. Troshichev, ${ }^{2}$ E. A. Bering,${ }^{3}$ V. O. Papitashvili ${ }^{4}$ \\ ${ }^{1}$ Australian Antarctic Division, Kingston, Hobart, Tasmania 7050, Australia \\ ${ }^{2}$ Arctic and Antarctic Research Institute, St Petersburg 194175, Russia \\ ${ }^{3}$ Department of Physics, Univerșity of Houston, Houston, TX 77204-5504, U.S.A. \\ ${ }^{4}$ Space Physics Research Laboratory, University of Michigan, Ann Arbor, MI 48109-214.3, U.S.A.
}

\begin{abstract}
The association of the European "Little Ice Age" (1550-1850; Lamb, 1982) with a period of significantly reduced solar activity (Eddy, 1976) suggests a significant mechanism of climate variation remains to be determined. Recent optical observations of connections between the tops of thunderstorm systems and altitudes of 70 $90 \mathrm{~km}$ (Sentman and Wescott, 1996) demonstrate a linkage between the troposphere and the lower reaches of the ionosphere. If thunderstorm development is affected by its electrical environment, then solar modulation of the geoelectric field provides a viable solarvariability-climate mechanism (see, e.g., Tinsley 1996). The high, dry Antarctic plateau provides an ideal site for demonstrating that solar variability can influence the geoelectric field. In this paper, we present evidence that the geoelectric field at Vostok is modulated by the duskward component of the Interplanetary Magnetic Field (IMF $B_{y}$ ) when Vostok rotates under the region magnetically linked to the dayside interaction region between the solar wind and the Earth's magnetic field.
\end{abstract}

\section{INTRODUGTION}

Thunderstorm activity draws current upward from the Earth. Some of this current returns to the Earth via the ionosphere. In this manner, global thunderstorm activitymaintains a time-varying electric potential of approx-imately $250 \mathrm{kV}$, directed downwards, between the equipotentials of the lower reaches of the ionosphere $(60-$ $90 \mathrm{~km}$ ) and the ground. In fair-weather regions, near ground level, a downward-directed geoelectric field of some $100 \mathrm{~V} \mathrm{~m}^{-1}$ can be measured. The geoelectric field is reponsive to global thunderstorm activity on time-scales of less than 1 hour. Measurements are optimised in regions where local diurnal variations in atmospheric conductivity are minor (principally over the oceans, in polar regions or high in some mountain regions). It is necessary to exclude data collected during periods of local electrical meteorological influence (high winds, falling or drifting snow and some types of cloud). Averaging to remove the day-to-day variability in global thunderstorm activity then results in a diurnal curve with a peak near 19UT, a minimum near 3UT and a range of some $30 \%$ of the mean. This is known as the global "fair weather" diurnal curve. Reiter (1992) provides a comprehensive review and background to geoelectricfield studies, and Bering (1995) gives a comprehensive interpretation of recent advances.

The hypothesis that the development of thunderstorm systems depends on the geoelectrical environment (see, e.g., Markson, 1981) remains controversial, but still has advocates. Recent accounts supporting this hypothesis include Tinsley and others (1989) and Tinsley (1996). Solar modulated galactic cosmic rays, sometimes supplemented by particles of solar origin, are postulated as the principal agent of solar influence on the geoelectric field. Cosmic rays control atmospheric conductivity in the crucial region between the tops of thunderstorms and the lower reaches of the ionosphere (see review by Pomerantz and Duggal, 1974).

Solar influences on the geoelectric field differ between mid-latitudes and the polar regions (Tinsley, 1996). Of specific relevance, a dawn-to-dusk potential is applied across the polar regions as a result of the interaction of the solar wind and the Earth's magnetic field (see, e.g., Tinsley and Heelis, 1993). The cross-polar potential results from the same interactions that generate auroral activity, and typically lies in the range $30-60 \mathrm{kV}$. It may, at times of increased solar activity, exceed $100 \mathrm{kV}$. The cross-polar potential may not be the dominant solar influence on the global geoelectric circuit, but it is of significant localised magnitude in the polar regions. The diurnal pattern generated as a station rotates beneath the cross-polar cap potential also aids detection.

Burns and others (1995) demonstrated that the fairweather diurnal curve could be extracted with difficulty from data collected at the Antarctic coastal station of Davis. Attempts to extract a solar influence from the Davis data were encouraging, but not conclusive due to remnant local influences. The difficulty of eliminating local influences at this coastal site has led to an international effort (Australia, Russia, U.S.A.) to re-establish a geoelectric-field observatory at Vostok. Deployment in planned for the 1997-98 austral summer. Vostok's high altitude, low average wind speed and minimal cloud cover are significant advantages for measurements of the geoelectric field. The long periods of either continuous darkness or continuous light also assist in limiting the diurnal variation in atmospheric conductiv- 

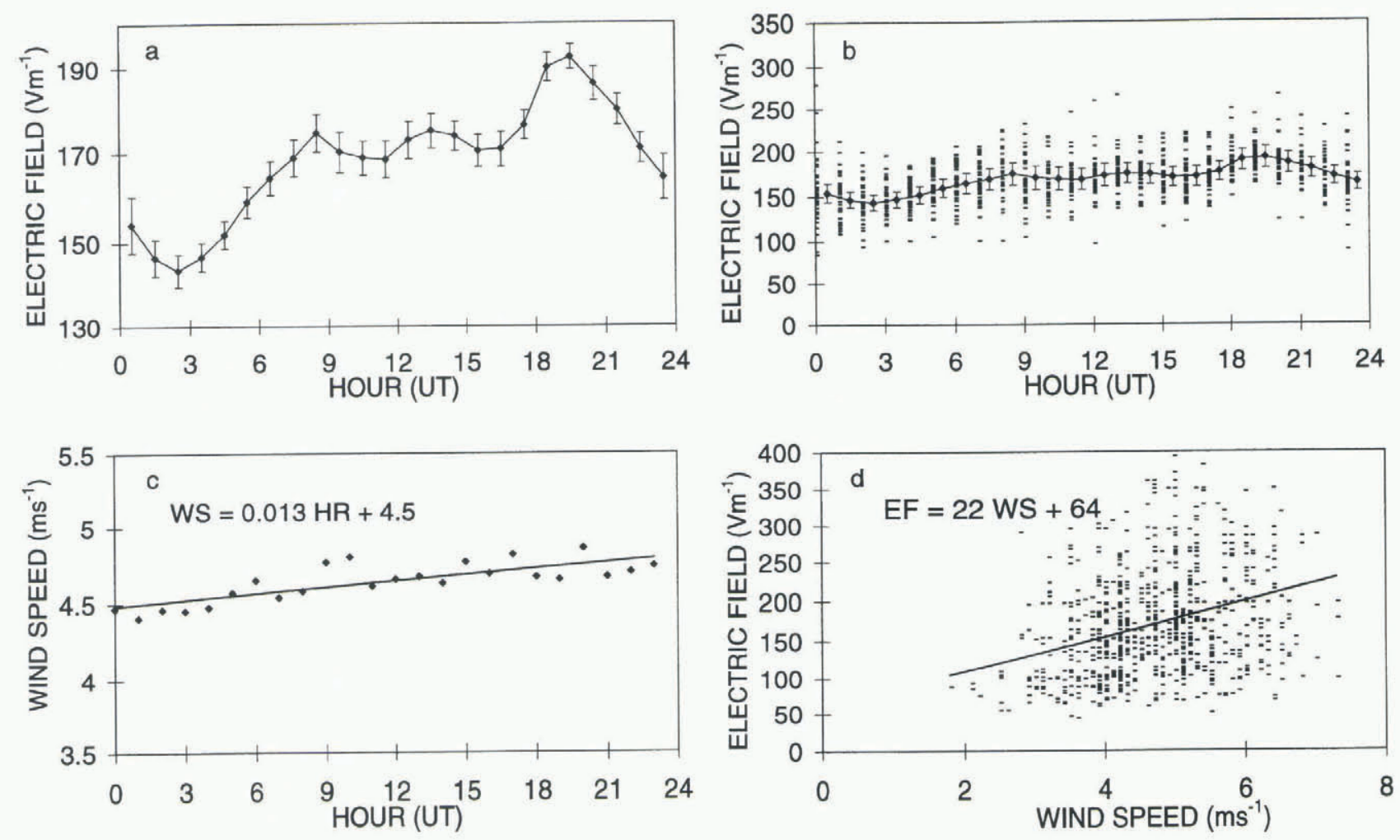

Fig. 1. (a) The average geoelectric-field diurnal curve of the 36 selected days. (b) All the scaled data that contribute to the average geoelectric-field diurnal curve. (c) The hourly average wind speed for the 36 selected days. (d) The relationship between the geoelectric field and wind speed.

ity which may complicate the interpretation of geoelectricfield measurements. The planned project can be significantly enhanced by the operation of geoelectric-circuit measuring instrumentation at other polar plateau sites. The plan to reopen the site led us to rescale and analyze a 7 month Vostok geoelectric-field dataset. Our purpose was to confirm that Vostok is a suitable site for a renewed effort.

\section{INSTRUMENTATION AND DATA}

A rotating dipole electric-field mill, as described by Park (1976), was operated at Vostok from 1974 through 1980 under a U.S.S.R.-U.S.A. cooperative research programme. The electric-field mill was operated approximately $1.5 \mathrm{~m}$ above the snow surface. Data were recorded on duplicated chart records, one for Soviet and one for American scientists. Park (1976) published an analysis of March-November 1974 data, and Soviet scientists incorporated some analysis of the Vostok data in their research on the geoelectric field in polar regions (Bandilet and others, 1982; Frank-Kamenetsky, 1983). We have been able to locate charts covering the interval May-December 1979, for which concurrent hourly meteorological data are available.

The chart data were scaled to determine the average geoelectric-field value at the midpoint of each UT hour. The data series is not complete over the interval. Times when the values were off-scale or rapidly varying due to local influences were not included in the dataset. Occasionally the instrument failed or charts and ink ran out. The calibration of the data is as initially determined for the equipment before it was deployed at Vostok in 1974. The possibility of variation in calibration with time is noted. To our knowledge, no further calibration of this instrumentation was undertaken.
Hourly-resolution wind-speed and -direction, temperature and pressure data are available, as well as a list of times when falling or drifting snow and ice was observed. The wind-speed data are derived from the wind run in the $10 \mathrm{~min}$ utes prior to the hour for which they are noted. Wind direction was noted, on the hour, to 16 compass-point accuracy.

The average daily value of the measured electric field varies considerably. So as to avoid a bias in the diurnal averages, our initial data selection was made on the basis that a complete 24 hours of electric-field values were available and suitable for analysis. Days when drifting or falling snow or ice was noted were rejected. The power station was located approximately $200 \mathrm{~m}$ to the northwest of the electric-field mill. When the wind was from the northwestern quadrant, occasional high values of the electric field were obtained. Typically the wind at Vostok comes from the west-southwest. Data were generally rejected when the wind came from the northwestern quadrant. We allowed some leniency when only a few of the 24 hourly wind direction values came from the edge of this quadrant and no effect on the electric-field data was apparent. In this manner, 36 days of data were selected for further investigation.

\section{ANALYSIS AND RESULTS}

Figure la shows the average diurnal curve of the 36 days of selected data. The long-term variation in the selected dataset was removed before estimating the uncertainties in the average diurnal curve. This was achieved by scaling the data such that each daily average equalled the average of the entire datset $\left(169 \mathrm{~V} \mathrm{~m}^{-1}\right)$. All scaled data are plotted separately in Figure 1b, using a wider-range plot. The error bars plotted in Figure la and b are \pm one standard error (standard deviation divided by the square root of the num- 
ber of samples). The average diurnal curve has a minimum at $2.5 \mathrm{UT}$, a maximum at $19.5 \mathrm{UT}$, a range of $29 \%$ of the mean value, and a shape broadly consistent with the fair-weather curve. A similar curve is derived from Vostok data by Park (1976), although the range is approximately $23 \%$ of the mean.

Plots of electric field against temperature and pressure show no consistent trend, but a significant relationship is apparent between electric field and wind speed. Plots of electric field against wind speed, and the average hourly wind-speed values for the 36 days are also shown in Figure $\mathrm{lc}$ and $\mathrm{d}$. The straight-line slope amounts to $22\left[\mathrm{~V} \mathrm{~m}^{-1}\right]$ per $\left[\mathrm{ms}^{-1}\right]$. The range of the average wind-speed values is $0.44 \mathrm{~m} \mathrm{~s}^{-1}$, corresponding to a possible electric-field variation of some $10 \mathrm{~V} \mathrm{~m}^{-1}$. This compares with the magnitude of the diurnal electric-field range of $49 \mathrm{~V} \mathrm{~m}^{-1}$. The possible wind-speed influence is sufficient to affect the estimate of the range, but not the general shape, of the average diurnal electric-field curve.
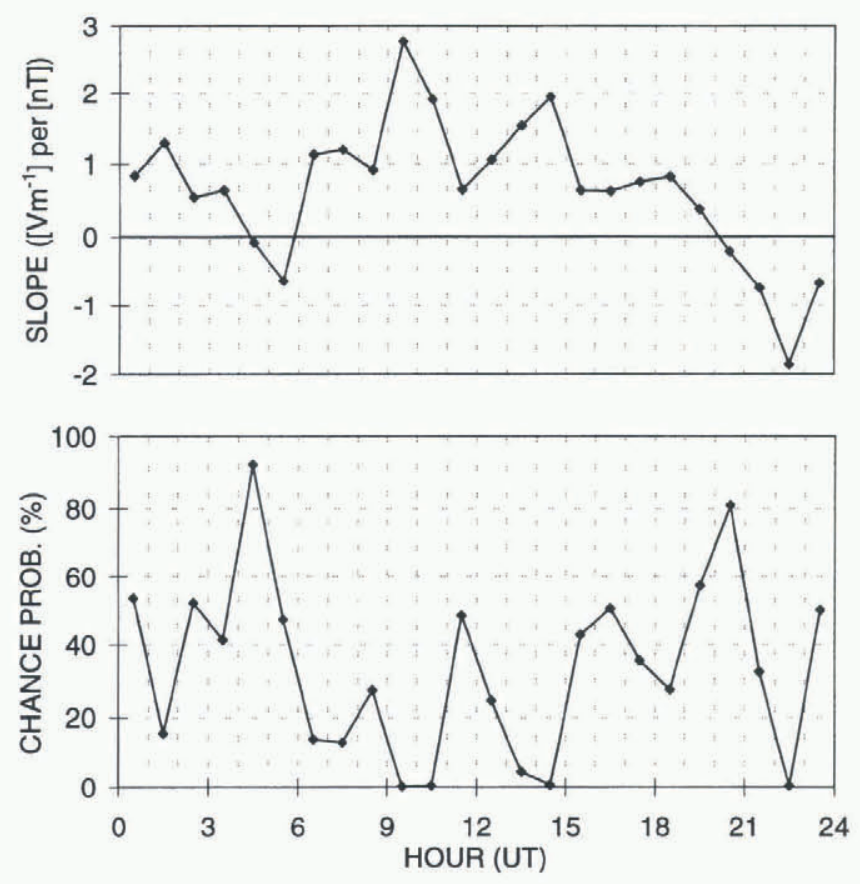

Fig. 2. The slope of the straight-line fit for the scaled geoelectric-field values and the IMF $B_{y}$ component, for each UT hour; and the probability that the association is due to chance.

A closer examination of the data suggests that some of the association of wind speed and electric field may be due to a chance association of a seasonal variation in the electric-field magnitudes and a seasonal variation in average wind speeds. When the date range of electric-field and wind-speed data compared is restricted to autumn (August-October: 18 days) the straight-line gradient reduces to $7\left[\mathrm{~V} \mathrm{~m}^{-1}\right]$ per $\left[\mathrm{m} \mathrm{s}^{-1}\right]$. Similarly for winter data (May-July: 13 days), the gradient is $14\left[\mathrm{~V} \mathrm{~m}^{-1}\right]$ per $\left[\mathrm{m} \mathrm{s}^{-1}\right]$.

Park (1976) reported a reduction in the daily average electric-field value measured at Vostok of 15\%, 1-3 days after the passage of a sector boundary of the Interplanetary Magnetic Field (IMF). A sector boundary is defined as when the general IMF orientation changes from toward the sun to away from the sun, or vice versa. The amount of data considered suitable from the 1979 dataset after consideration of known meteorological influences is insufficient for a direct repeat of Park's analysis. We investigate the association of IMF $B_{y}$ and the geoelectric field in order to define more directly the nature of the solar influence. Tinsley and Heelis (1993) discuss the magnitude of IMF $B_{y}$ influences on the geoelectric field expected via changes in solar-wind-induced plasma convection at high-latitude polar sites.

Plotted in Figure 2 is the slope $\left(\left[\mathrm{V} \mathrm{m}^{-1}\right]\right.$ per $\left.[\mathrm{nT}]\right)$ obtained from straight-line fits of the scaled electric-field values against IMF $B_{y}$, for each UT hour. IMF $B_{y}$ measurements were not available at all times, and the number of pairs of points available for each UT hour ranged from 33 to 36 . The probability that the straight line is due to chance is plotted separately in Figure 2. The chance correlations are less than 5\% for five hours: 9UT (for convenience, the value centred on 9.5UT is listed in this manner; similarly for other times in the description which follows), 10UT, 13UT and 14UT when the slope is positive and of average magnitude 2 $\left[\mathrm{V} \mathrm{m}^{-1}\right]$ per [nT], and 22UTwhen the slope is negative. The probability that the correlations for these hours are due to chance are 9UT $0.14 \%$; 10UT $0.43 \%$; 13UT $4.7 \%$; 14UT $0.64 \%$; and 22UT $0.5 \%$. Figure 3 shows a combined plot of the 9UT, 10UT, 13UT and 14UT scaled electric-field values, further adjusted by subtracting the average diurnal value of the appropriate hour to allow intercomparison, against the IMF $B_{y}$ values. A straight line yielding a slope of 0.7 $\left[\mathrm{V} \mathrm{m}^{-1}\right]$ per $[\mathrm{nT}]$ best fits these data.

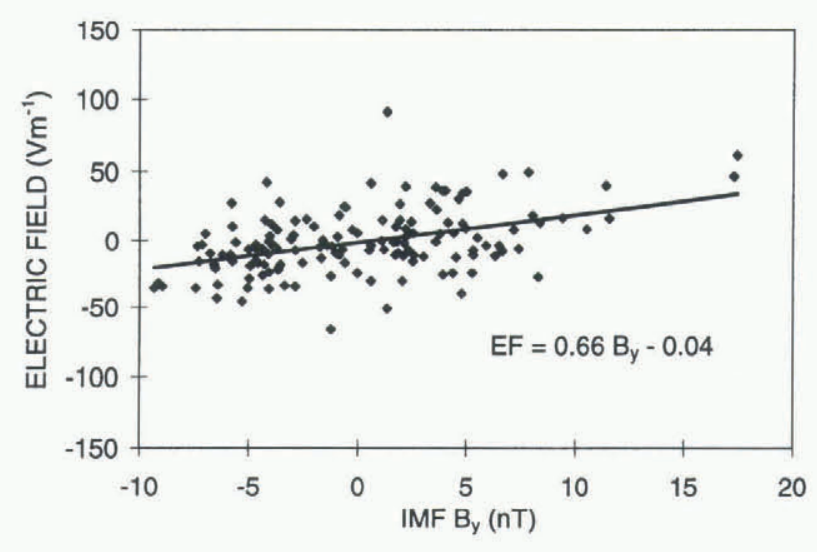

Fig. 3. Scaled geoelectric-field values, corrected for average diurnal trends, for 9UT, 10UT, 13UTand 14UT, compared with the IMF B $B_{y}$ component.

The manner in which the electric-field data are scaled, combined with the fact that for a large fraction of the individual UT hours the association with IMF $B_{y}$ is positive, means that we have likely reduced the magnitude and significance of the association. Forcing each daily average electric-field value to be equal to the grand average of the 36 days has also likely generated the "significant" negative correlation at 22UT. The scaling is, however, desirable to reduce the large variation in the absolute magnitude of the electric-field values which may be due to changes in local conductivity, wind-speed influences and variations in the daily global thunderstorm activity.

Both the electric field and IMF $B_{y}$ are self-correlated over intervals longer than the hourly separation of data points. However, we decided to ivestigate the relationship between IMF $B_{y}$ and the scaled electric-field values, which were further corrected to allow for the average diurnal trend depicted in Figure 1, across the 6-18UT time range 
for which contiguous positive correlations in excess of 0.5 $\left[\mathrm{V} \mathrm{m}^{-1}\right]$ per $[\mathrm{nT}]$ were measured for the individual UT hour correlations. To achieve a reasonable correlation it is necessary for a range of IMF $B_{y}$ values to be recorded across the time interval selected, so not all days can be expected to yield significant correlations. To make some allowance for chance associations, only linear fits with "random" chance correlations of $<1 \%$ are considered. Nine of the 36 selected days met this criterion, eight of which yielded positive slopes. Two large-magnitude slopes of $-8.5\left[\mathrm{~V} \mathrm{~m}^{-1}\right]$ per $[\mathrm{nT}]$ and $+15\left[\mathrm{~V} \mathrm{~m}^{-1}\right]$ per $[\mathrm{nT}]$ were measured; the remainder yielded an average slope of $4\left[\mathrm{~V} \mathrm{~m}^{-1}\right]$ per $[\mathrm{nT}]$.

\section{DISGUSSION AND CONGLUSIONS}

This analysis has confirmed the result of Park (1976), that the global fair-weather geoelectric-field curve can be observed at Vostok. This high, Antarctic-plateau site has a considerable advantage for recording geoelectric-field data relatively free of local contamination, compared with the coastal Antarctic site of Davis.

IMF $B_{y}$ is significantly positively correlated with the geoelectric field at 9UT, 10UT, 13UT and 14UT, when Vostok is magnetically linked to the dayside interaction region between the solar wind and the Earth's magnetic field. Magnetic noon at Vostok occurs near 13UT. The positive association of geoelectric field and IMF $B_{y}$ appears on occasions to persist while Vostok rotates across the magnetic footprint of the entire dayside magnetosphere. The magnitude is of the order of $3\left[\mathrm{~V} \mathrm{~m}^{-1}\right]$ per $[\mathrm{nT}]$.

We have been able to show a more direct association of solar variability and the geoelectric field at Vostok than was reported by Park (1976), but a direct test of the Park result requires a larger dataset.

\section{ACKNOWLEDGEMENTS}

The electric-field measurements at Vostok, Antarctica (1974-80), were carried out under a Soviet-American cooperative research agreement. Funding for collaborative visits by Russian scientists to the Australian Antarctic Division for work on this project was provided by the Australian Antarctic Foundation. The assistance of J. French with computing advice and I. Smolskaia with some Russian transliteration is gratefully acknowledged.

\section{REFERENCES}

Bandilet, O. I., T.V. Kozelova, S. P. Chernysheva and V. M. Sheftel. 1982. O prirode vertikalnoi komponenti geoelektricheskogo polya vo vremya magnitnix vosmuschenii [About the nature of the vertical component of the electric field during magnetic disturbances]. Geomagnetizm $i$ Aeronomiya, 22(6), 1028-1029.

Bering, E. A., III. 1995. The global circuit: global thermometer, weather byproduct or climate modulator? Rev. Geophys., 33(2), Supplement, 845-862.

Burns, G. B., M. H. Hesse, S. K. Parcell, S. Malachowski and K. D. Cole. 1995. The geoelectric field at Davis Station, Antarctica. 7. Atmos. Terr. Phys., 57(14), 1783-1797.

Eddy, J. A. 1976. The Maunder minimum. Science, 192(4245), 1189-1202.

Frank-Kamenetskiy, A.V. 1983. Nekotoryye kharakteristiki varitsiy vertikalnoy komponenty atmosfernogo elektricheskogo polya po dannym st. Vostok [Features of the vertical atmospheric electric field at Vostok Station]. In Kanonidi, Kh. D., V. G. Kobzev, A. I. Laptukhov, L. V. Petrova, I. G. Simakov and V. M. Sheftel, eds. Atmosfernoye elektrichestvo i magnitosfernye vozmuscheniya [Atmospheric electricity and magnetospheric disturbances 7. Moscow, Akademii Nauk. IZMIRAN, 91-98.

Lamb, H. H. 1982. Climate, history and the modern world. London and New York, Methuen \& Co.

Markson, R. 1981. Modulation of the Earth's electric field by cosmic radiation. Nature, 291 (5813), 304-307.

Park, C. G. 1976. Solar magnetic sector effects on the vertical atmospheric electric field at Vostok, Antarctica. Geophys. Res. Lett., 3(8), 475-478.

Pomerantz, M. A. and S. P. Duggal. 1974. The sun and cosmic rays. Rev. Geophys. Space Phys., 12(3), 343-361.

Reiter, R. 1992. Phenomena in atmospheric and environmental electricity. Amsterdam, etc., Elsevier.

Sentman, D. D. and E. M. Wescott. 1996. Red sprites and blue jets: high latitude optical emissions linked to lightning. EOS, 77 (1), 1-4.

Tinsley, B. A. 1996. Correlations of atmospheric dynamics with solar windinduced changes of air-earth current density into cloud tops. J. Geophys. Res., 101 (D23), 29,701-29,714.

Tinsley, B. A. and R. A. Heelis. 1993. Correlations of atmospheric dynamics with solar activity: evidence for a connection with the solar wind, atmospheric electricity, and cloud microphysics. 7. Geophys. Res., 98(D6), $10,375-10,384$.

Tinsley, B. A., G. M. Brown and P. H. Scherrer. 1989. Solar variability influences on weather and climate: possible connections through cosmic ray fluxes and storm intensification. 7. Geophys. Res., 94(D12), 14,783-14,792. 